\title{
Multi-criteria decision making approaches for supplier evaluation and selection:
}

\section{a literature review}

\author{
William Ho ${ }^{*}$, Xiaowei Xu and Prasanta K. Dey \\ Operations and Information Management Group \\ Aston Business School, Aston University \\ Birmingham B4 7ET, United Kingdom \\ *E-mail: w.ho@aston.ac.uk; Tel: +44 (0)121 2043342
}

\begin{abstract}
Supplier evaluation and selection problem has been studied extensively. Various decision making approaches have been proposed to tackle the problem. In contemporary supply chain management, the performance of potential suppliers is evaluated against multiple criteria rather than considering a single factor - cost. This paper reviews the literature of the multi-criteria decision making approaches for supplier evaluation and selection. Related articles appearing in the international journals from 2000 to 2008 are gathered and analyzed so that the following three questions can be answered: (i) which approaches were prevalently applied? (ii) which evaluating criteria were paid more attention to? (iii) is there any inadequacy of the approaches? Based on the inadequacy, if any, some improvements and possible future work are recommended. This research not only provides evidence that the multi-criteria decision making approaches are better than the traditional cost-based approach, but also aids the researchers and decision makers in applying the approaches effectively.
\end{abstract}

Keywords: Supplier evaluation; Supplier selection; Multi-criteria decision making. 


\section{Introduction}

The contemporary supply management is to maintain long term partnership with suppliers, and use fewer but reliable suppliers. Therefore, choosing the right suppliers involves much more than scanning a series of price list, and choices will depend on a wide range of factors which involve both quantitative and qualitative. Extensive multi-criteria decision making approaches have been proposed for supplier selection, such as the analytic hierarchy process (AHP), analytic network process (ANP), case-based reasoning (CBR), data envelopment analysis (DEA), fuzzy set theory, genetic algorithm (GA), mathematical programming, simple multi-attribute rating technique (SMART), and their hybrids.

There are at least three journal articles reviewing the literature regarding supplier evaluation and selection models (Weber et al., 1991; Degraeve et al., 2000; De Boer et al., 2001). Since these articles review the literature up to 2000, this paper extends them by surveying the multi-criteria supplier evaluation and selection approaches through a literature review and classification of the international journal articles from 2000 to 2008. Based on the 78 journal articles collected (searched via Emerald, Ingenta, MetaPress, ProQuest, and ScienceDirect), three issues are examined, including: (i) which approaches were prevalently applied? (ii) which evaluating criteria were paid more attention to? (iii) is there any inadequacy of the approaches?

The paper is organized as follows. Sections 2 and 3 describe the individual approaches and integrated approaches critically, respectively. Section 4 analyses the most prevalently used approaches, discusses the most popular evaluating criteria, and find out the limitations of the approaches. Section 5 suggests for future work. Section 6 concludes the paper.

\section{Individual approaches}

\subsection{Data envelopment analysis}

14 out of 78 articles (17.95\%) applied DEA in the supplier selection process. Their applications and evaluating criteria used in the approaches are summarized in Appendix 1.

Based on the work in Baker and Talluri (1997), Braglia and Petroni (2000) applied DEA to measure the efficiencies of alternative suppliers. Nine evaluating factors were proposed to measure each supplier rating. To avoid selecting a sub-optimal or "false positive" supplier, both cross-efficiency and Maverick index were measured.

Liu et al. (2000) proposed a simplified DEA model to evaluate the overall performances of suppliers with respect to three input and two output criteria. The model aimed at selecting a supplier having higher supply variety so that the number of suppliers can be reduced. 
Forker and Mendez (2001) applied DEA to measure the comparative efficiencies of suppliers. For each supplier, a measure of comparative efficiency was calculated as the maximum ratio of a single input to multiple outputs. Those outputs were based on the critical factors of quality management proposed by other scholars. Similar to Braglia and Petroni (2000), the cross-efficiencies were calculated to find the "best peer" suppliers.

Narasimhan et al. (2001) applied DEA model to evaluate alternative suppliers for a multinational corporation in the telecommunications industry. 11 evaluating factors were considered in the model, in which there are six inputs related to the supplier capability, and five outputs related to the supplier performance. Based on the performance score, the suppliers were classified into four categories: high performers and efficient, high performers and inefficient, low performers and efficient, and low performers and inefficient.

Talluri and Baker (2002) used a three-phase approach for the logistics distribution network design. Potential stakeholders, including suppliers, manufacturers, and distributors were evaluated individually in Phase I using DEA. The authors used six evaluating factors proposed by other scholars for supplier evaluation, in which there are two inputs and four outputs. Based on the performance scores obtained in Phase I and the optimal number of stakeholders to be utilized obtained in Phase II, the optimal routing of material from selected suppliers to manufacturers to warehouses were identified.

Talluri and Sarkis (2002) applied DEA to measure the performance of suppliers. The authors used the same evaluating factors and dataset as that in Talluri and Baker (2002) to illustrate how the model works.

Talluri and Narasimhan (2004) applied DEA for effective supplier sourcing. The approach is similar to that in Narasimhan et al. (2001), except that Narasimhan et al. (2001) used simple efficiency scores in the analysis, whereas Talluri and Narasimhan (2004) used cross-efficiencies and statistical methods in categorizing the supply base into various clusters.

Garfamy (2006) applied DEA to measure the overall performances of suppliers based on total cost of ownership concept. A supplier providing a single unit of output charging the least amount of costs was regarded as the most efficient.

Ross et al. (2006) used DEA to evaluate the supplier performance with respect to both buyer and supplier performance attributes. Three sensitivity analyses were carried out. The first analysis was to compute the supplier efficiency scores without considering the evaluation team's weights and bounds. The second analysis considered the evaluation team's preferences on the supplier performance attributes, whereas the third analysis considered the buyer's preferences on the supplier performance attributes. 
Saen (2006) developed a DEA model to evaluate technology suppliers with respect to three factors, in which there was a qualitative factor - amount of know-how transfer. A five-point scale was deployed to rank the suppliers in terms of the qualitative factor.

Seydel (2006) used DEA to tackle the supplier selection problem. Unlike the above approaches, there was no input considered in the model. A seven-point scale was deployed to assign ratings to the qualitative criteria. The author addressed that the proposed DEA required less involvement of decision makers than SMART.

Talluri et al. (2006) presented a so-called chance-constrained DEA approach to evaluate the performance of suppliers in the presence of stochastic performance measures. Price was considered as an input, whereas quality and delivery were used as outputs. The model was compared with the deterministic DEA to highlight its usefulness.

Saen (2007a) presented a so-called imprecise DEA to evaluate the performance of suppliers in the presence of both quantitative and qualitative data. The author addressed that the supplier reputation (SR), one of the output measures considered in the case study, could not be quantified legitimately. The proposed model allowed the decision makers to provide a complete rank ordering of the suppliers on SR. Besides, the proposed model could handle the fuzzy data in the forms of bounded data.

Wu et al. (2007) presented a so-called augmented imprecise DEA for supplier selection. The proposed model was able to handle imprecise data (i.e., to rank the efficient suppliers) and allow for increased discriminatory power (i.e., to discriminate efficient suppliers from poor performing suppliers). A web-based system was developed to allow potential buyers for supplier evaluation and selection.

\subsection{Mathematical programming}

Among 78 journal articles, nine papers (11.54\%) formulated the supplier selection problem as various types of mathematical programming models. Their applications and evaluating criteria used in the approaches are summarized in Appendix 2.

\subsubsection{Linear programming}

Talluri and Narasimhan (2003) is the first group of researchers considering performance variability measures in evaluating alternative suppliers. The researchers developed two linear programming models to maximize and minimize the performance of a supplier against the best target measures set by the buyer. Measuring both maximum and minimum efficiencies of each supplier would achieve a comprehensive understanding of a supplier performance. 
Talluri and Narasimhan (2005) developed a linear programming model to evaluate and select potential suppliers with respect to the strengths of existing suppliers and exclude underperforming suppliers from a telecommunications company's supply base. The model was compared with traditional and advanced DEA to examine its relative advantages.

$\mathrm{Ng}$ (2008) developed a weighted linear programming model for the supplier selection problem, with an objective of maximizing the supplier score. Similar to AHP, it involves the decision makers in determining the relative importance weightings of criteria.

\subsubsection{Integer linear programming}

Talluri (2002) developed a binary integer linear programming model to evaluate alternative supplier bids based on ideal targets for bid attributes set by the buyer, and to select an optimal set of bids by matching demand and capacity constraints. Based on four variations of model, effective negotiation strategies were proposed for unselected bids.

Hong et al. (2005) presented a mixed-integer linear programming model for the supplier selection problem. The model was to determine the optimal number of suppliers, and the optimal order quantity so that the revenue could be maximized. The change in suppliers' supply capabilities and customer needs over a period of time were considered.

\subsubsection{Integer nonlinear programming}

Ghodsypour and O’Brien (2001) formulated a mixed integer nonlinear programming model to solve the multi-criteria sourcing problem. The model was to determine the optimal allocation of products to suppliers so that the total annual purchasing cost could be minimized. Three constraints were considered in the model.

\subsubsection{Goal programming}

Karpak et al. (2001) constructed a goal programming (GP) model to evaluate and select the suppliers. Three goals were considered in the model, including cost, quality, and delivery reliability. The model was to determine the optimal amount of products ordered, while subjecting to buyer's demand and supplier's capacity constraints.

\subsubsection{Multi-objective programming}

Narasimhan et al. (2006) constructed a multi-objective programming model to select the optimal suppliers and determine the optimal order quantity. Five criteria were proposed to evaluate the performance of suppliers. Before solving the model to optimality, the relative 
importance weightings of five criteria were derived in advance. The authors suggested that AHP could be one of the possible ways for generating the weightings.

Wadhwa and Ravindran (2007) modeled the supplier selection problem as a multi-objective programming problem, in which there are three objective functions, such as minimization of price, lead time, and rejects. Three solution approaches, including weighted objective method, goal programming method, and compromise programming, were used to compare the solutions.

\subsection{Analytic hierarchy process}

There are seven (8.97\%) out of 78 journal articles proposing AHP to deal with the supplier selection problem. Their applications and evaluating criteria used in the approaches are summarized in Appendix 3.

Akarte et al. (2001) developed a web-based AHP system to evaluate the casting suppliers with respect to 18 criteria. In the system, suppliers had to register, and then input their casting specifications. To evaluate the suppliers, buyers had to determine the relative importance weightings for the criteria based on the casting specifications, and then assigned the performance rating for each criterion using a pairwise comparison.

Muralidharan et al. (2002) proposed a five-step AHP-based model to aid decision makers in rating and selecting suppliers with respect to nine evaluating criteria. People from different functions of the company, such as purchasing, stores, and quality control, were involved in the selection process.

Chan (2003) developed an interactive selection model with AHP to facilitate decision makers in selecting suppliers. The model was so-called because it incorporated a method called chain of interaction, which was deployed to determine the relative importance of evaluating criteria without subjective human judgment. AHP was only applied to generate the overall score for alternative suppliers based on the relative importance ratings.

Chan and Chan (2004) applied AHP to evaluate and select suppliers. The AHP hierarchy consists of six evaluating criteria and 20 sub-factors, of which the relative importance ratings were computed based on the customer requirements.

Liu and Hai (2005) applied AHP to evaluate and select suppliers. Similar to Chan (2003), the authors did not apply the AHP's pairwise comparison to determine the relative importance ratings among the criteria and sub-factors. Instead, the authors used Noguchi's voting and ranking method, which allowed every manager to vote or to determine the order of criteria instead of the weights. 
Chan et al. (2007) developed an AHP-based decision making approach to solve the supplier selection problem. Potential suppliers were evaluated based on 14 criteria. A sensitivity analysis using Expert Choice was performed to examine the response of alternatives when the relative importance rating of each criterion was changed.

Hou and Su (2007) developed an AHP-based decision support system for the supplier selection problem in a mass customization environment. Factors from external and internal influences were considered to meet the needs of markets within the global changing environment.

\subsection{Case-based reasoning}

Same as AHP, seven papers (8.97\%) used CBR to evaluate and select suppliers. Their applications and evaluating criteria used in the approaches are summarized in Appendix 4.

Choy and Lee (2002) presented a generic model using the CBR technique for supplier selection. Various evaluating criteria were grouped into three categories: technical capability, quality system, and organizational profile. The model was implemented in a consumer products manufacturing company, which had stored the performance of past suppliers and their attributes in a database system. The proposed model would then retrieve or select a supplier who met the specification predefined by the company most.

Choy et al. (2002), Choy and Lee (2003), Choy et al. (2003a), Choy et al. (2003b), Choy et al. (2004a), and Choy et al. (2005) applied the CBR-based model to aid decision makers in the supplier selection problem again. The approach was very similar to that proposed in Choy and Lee (2002), including the supplier selection workflow. In addition, the model was deployed to the same company. The only difference is due to the supplier evaluating factors, as shown in Appendix 4.

\subsection{Analytic network process}

Three papers (3.85\%) proposed ANP to tackle the supplier selection problem. Their applications and evaluating criteria used in the approaches are summarized in Appendix 5.

Sarkis and Talluri (2002) believed that supplier evaluating factors would influence each other, and the internal interdependency needed to be considered in the evaluation process. The authors applied ANP to evaluate and select the best supplier with respect to organizational factors and strategic performance metrics, which consist of seven evaluating criteria. The impact of these factors among themselves was considered.

Bayazit (2006) proposed an ANP model to tackle the supplier selection problem. There 
were ten evaluating criteria in the model, which were classified into supplier's performance and capability clusters. To formulate interrelationships among all criteria, each of them was considered as a controlling factor for a pairwise comparison matrix.

Gencer and Gürpinar (2007) implemented an ANP model in an electronic company to evaluate and select the most appropriate supplier with respect to various supplier evaluating criteria, which were classified into three clusters. The interrelationships among the criteria were considered in the selection process.

\subsection{Fuzzy set theory}

Three papers (3.85\%) utilized fuzzy set theory in the supplier selection process. Their applications and evaluating criteria used in the approaches are summarized in Appendix 6.

Chen et al. (2006) presented a hierarchy model based on fuzzy-sets theory to deal with the supplier selection problem. The linguistic values were used to assess the ratings and weights for the supplier evaluating factors. These linguistic ratings could be expressed in trapezoidal or triangular fuzzy numbers. The proposed model was capable of dealing with both quantitative and qualitative criteria.

Sarkar and Mohapatra (2006) suggested that performance and capability were two major measures in the supplier evaluation and selection problem. The authors used the fuzzy set approach to account for the imprecision involved in numerous subjective characteristics of suppliers. A hypothetical case was adopted to illustrate how the two best suppliers were selected with respect to four performance-based and ten capability-based factors.

Florez-Lopez (2007) picked up 14 most important evaluating factors from 84 potential added-value attributes, which were based on the questionnaire response from US purchasing managers. To obtain a better representation of suppliers' ability to create value for the customers, a two-tuple fuzzy linguistic model was illustrated to combine both numerical and linguistic information. Besides, the proposed model could generate a graphical view showing the relative suitability of suppliers and identifying strategic groups of suppliers.

\subsection{Simple multi-attribute rating technique}

Two papers (2.56\%) used SMART to solve the supplier selection problem. Their applications and evaluating criteria used in the approaches are summarized in Appendix 7.

Barla (2003) conducted a five-step approach based on SMART for supplier evaluation and selection in a glass manufacturing company. In the methodology, seven evaluating criteria were proposed, of which there were multiple sub-factors to be considered. A 
subcontractor getting the highest score, called the total expected utilities, would be selected.

Huang and Keskar (2007) presented a comprehensive set of 101 metrics, collected from the literature, for supplier selection. Instead of using all metrics, the authors selected some of the relevant criteria and metrics for the selection process.

\subsection{Genetic algorithm}

There is only one paper (1.28\%) using GA in the supplier selection process. Its application and evaluating criteria used in the approach are summarized in Appendix 8.

Ding et al. (2005) presented a GA based optimization methodology for supplier selection. The proposed method provided possible configurations of the selected suppliers, including transportation modes. Each configuration was then evaluated with respect to the key performance indicators.

\section{Integrated approaches}

\subsection{Integrated AHP approaches}

14 papers (17.95\%) applied integrated AHP approaches to evaluate the performance of suppliers and select the best supplier. Their applications and evaluating criteria used in the approaches are summarized in Appendix 9.

\subsubsection{Integrated AHP and Bi-negotiation}

Chen and Huang (2007) integrated AHP and a multi-attribute negotiation mechanism for the supplier selection problem. The model enabled the buyers and suppliers to negotiate on multi-attributes for a deal, including assets, business criteria, cost, and delivery.

\subsubsection{Integrated AHP and DEA}

Ramanathan (2007) suggested that DEA could be used to evaluate the performance of suppliers using both quantitative and qualitative information obtained from the total cost of ownership and AHP. Specifically, costs based on the concept of total cost of ownership were regarded as inputs, whereas the AHP weights were considered as outputs in the DEA model.

Saen (2007b) proposed an integrated AHP-DEA approach to evaluate and select slightly non-homogeneous suppliers. The author stated that many suppliers do not comprehensively consume common inputs to comprehensively supply common outputs. In the approach, AHP was deployed to determine the relative weight of each supplier that had missing value (i.e., input or output). DEA was then applied to compute the relative efficiency of each supplier. 
Sevkli et al. (2007) applied an integrated AHP-DEA approach for supplier selection. In the approach, AHP was used to derive local weights from a given pairwise comparison matrix, and aggregate local weights to yield overall weights. Each row and column of the matrix was assumed as a decision making unit (DMU) and an output, respectively. A dummy input that had a value of one for all DMUs was deployed in DEA to calculate the efficiency scores of all suppliers. However, the authors pointed out that the approach was relatively more cumbersome to apply than the individual AHP.

\subsubsection{Integrated AHP, DEA, and artificial neural network}

Ha and Krishnan (2008) applied an integrated approach in an auto parts manufacturing company for supplier selection. 12 evaluating criteria were proposed for the selection problem. In the approach, AHP was used first to evaluate the performance of suppliers with respect to five qualitative factors. Then, the remaining seven quantitative criteria along with the scores for each supplier calculated by AHP were passed to DEA and artificial neural network (ANN) to measure the performance efficiency of each supplier. Both results were compiled into one efficiency index using a simple averaging method.

\subsubsection{Integrated $A H P$ and $G P$}

Çebi and Bayraktar (2003) proposed AHP to evaluate the relative performance of suppliers for every raw material with respect to 14 evaluating criteria. The weightings of suppliers were then used as the input of a GP model to select the best set of suppliers for a particular type of raw materials, and determine the amount of raw materials to be purchased.

Similar to Çebi and Bayraktar (2003), Wang et al. (2004; 2005) applied an integrated AHP-GP approach for supplier selection. The only difference between them is due to the evaluating criteria used in AHP. The AHP weightings were incorporated into one of the goal constraints of the GP model.

Perçin (2006) applied an integrated AHP-GP approach for supplier selection. AHP was used first to measure the relative importance weightings of potential suppliers with respect to 20 evaluating factors. The weightings were then used as the coefficients of five objective functions in the GP model. The model was to determine the optimal order quantity from the most appropriate supplier while considering the capacities of potential suppliers.

Kull and Talluri (2008) utilized an integrated AHP-GP approach to evaluate and select suppliers with respect to risk factors and product life cycle considerations. In the proposed model, AHP was used to assess suppliers along the risk criteria, and to derive risk scores. The 
GP model was then constructed to evaluate alternative suppliers based on multiple risk goals and various hard constraints.

Mendoza et al. (2008) presented an integrated AHP-GP approach to reduce a large number of potential suppliers to a manageable number, rank the alternative suppliers with respect to five evaluating criteria, and determine the optimal order quantity.

\subsubsection{Integrated AHP and grey relational analysis}

Yang and Chen (2006) applied AHP to compute relative importance weightings of qualitative criteria. The weightings were then used as coefficients of grey relational analysis model. The model would combine the qualitative and quantitative data to yield the grey relational grade values. A supplier with the highest value was regarded as the best supplier.

\subsubsection{Integrated AHP and mixed integer nonlinear programming}

Mendoza and Ventura (2008) proposed a two-stage method to deal with the supplier selection and order quantity problems simultaneously. At the first stage, AHP was applied to rank and reduce a list of suppliers to a manageable number with respect to five evaluating criteria, as suggested by Mendoza et al. (2008). Second, the mixed integer nonlinear programming model was constructed to determine the optimal order quantity.

\subsubsection{Integrated AHP and multi-objective programming}

Xia and Wu (2007) incorporated AHP into the multi-objective mixed integer programming model for supplier selection. The model applied AHP to calculate the performance scores of potential suppliers first. The scores were then used as coefficients of one of the four objective functions. The model was to determine the optimal number of suppliers, select the best set of suppliers, and to determine the optimal order quantity.

\subsection{Integrated fuzzy approaches}

Nine papers (11.54\%) proposed integrated fuzzy approaches to deal with the supplier evaluation and selection problem. Their applications and evaluating criteria used in the approaches are summarized in Appendix 10.

\subsubsection{Integrated fuzzy and $A H P$}

Kahraman et al. (2003) applied a fuzzy AHP to select the best supplier in a Turkish white good manufacturing company. Decision makers could specify preferences about the 
importance of each evaluating criterion using linguistic variable.

Chan and Kumar (2007) also used a fuzzy AHP for supplier selection as the case with Kahraman et al. (2003). In the approach, triangular fuzzy numbers and fuzzy synthetic extent analysis method were used to represent decision makers' comparison judgment and decide the final priority of different criteria.

\subsubsection{Integrated fuzzy, $A H P$, and cluster analysis}

Bottani and Rizzi (2008) developed an integrated approach for supplier selection. The approach integrated cluster analysis and AHP to group and rank alternatives, and to progressively reduce the amount of alternatives and select the most suitable cluster. Fuzzy logic was also brought in to cope with the intrinsic qualitative nature of the selection process.

\subsubsection{Integrated fuzzy and GA}

Jain et al. (2004) suggested a fuzzy based approach for supplier selection. The authors addressed that it might be difficult for an expert to define a complete rule set for evaluating the supplier performance. GA was therefore integrated to generate a number of rules inside the rule set according to the nature and type of the priorities associated with the products and their supplier's attributes.

\subsubsection{Integrated fuzzy and multi-objective programming}

Amid et al. (2006) developed a fuzzy multi-objective linear programming model for supplier selection. The model could handle the vagueness and imprecision of input data, and help the decision makers to find out the optimal order quantity from each supplier. Three objective functions with different weights were included in the model. An algorithm was developed to solve the model.

Amid et al. (2008) formulated a fuzzy multi-objective mixed integer linear programming model to solve the supplier selection problem. The approach is very similar to that in Amid et al. (2006), including the number of objective functions in the model, the criteria used to evaluate the suppliers, and the solution approach used to solve the model. The only difference is that quantity discount was considered in Amid et al. (2008). The price discount was directly proportional to the quantities ordered.

\subsubsection{Integrated fuzzy and quality function deployment}

Bevilacqua et al. (2006) applied quality function deployment (QFD) approach for 
supplier selection. A house of quality was constructed to identify the features that the purchased product should have in order to satisfy the customers' requirements, and then to identify the relevant supplier assessment criteria. The importance of product features and the relationship weightings between product features and assessment criteria were assigned in terms of fuzzy variables. Finally, the potential suppliers were evaluated against the criteria.

\subsubsection{Integrated fuzzy and SMART}

Kwong et al. (2002) integrated fuzzy set theory into SMART to assess the performance of suppliers. The supplier assessment forms were used first to determine the scores of individual assessment items, and then the scores were input to a fuzzy expert system for the determination of supplier recommendation index.

Chou and Chang (2008) applied a fuzzy SMART approach to evaluate the alternative suppliers in an IT hardware manufacturing company. A sensitivity analysis was carried out to assess the impact of changes in the risk coefficients in terms of supplier ranking order.

\subsection{Other approaches}

Many other integrated approaches (nine papers or $11.54 \%$ ) were proposed. Their applications and evaluating criteria used in the approaches are summarized in Appendix 11.

\subsubsection{Integrated $A N N$ and $C B R$}

Choy et al. (2003c; 2004b) developed an integrated ANN and CBR approach to select the best supplier. Specifically, ANN was used to benchmark the potential suppliers, whereas CBR was used to select the best supplier based on the previous successful and relevant cases.

\subsubsection{Integrated $A N N$ and $G A$}

Lau et al. (2006) developed an integrated ANN and GA approach for supplier selection. ANN was responsible for benchmarking the potential suppliers with respect to four evaluating factors. After that, GA was deployed to determine the best combination of suppliers. The four evaluating criteria were used again in the fitness function of GA.

\subsubsection{Integrated ANP and multi-objective programming}

Demirtas and Üstün (2008) developed an integrated ANP and multi-objective mixed integer linear programming approach to select the best set of suppliers, and to determine the optimal order allocation. Performance of potential suppliers was evaluated using ANP against 
14 assessment criteria. The priorities were then incorporated into one of the three objective functions.

\subsubsection{Integrated ANP and GP}

Demirtas and Üstün (2009) developed an integrated ANP and GP approach for supplier selection. Similar to Demirtas and Üstün (2008), potential suppliers were evaluated using ANP first. The weightings were then used as coefficients of one of the three objective functions. All evaluating criteria and objective functions are exactly the same as those in Demirtas and Üstün (2008). The only difference is that a GP model was constructed in which there were four goals.

\subsubsection{Integrated DEA and multi-objective programming}

Weber et al. (2000) constructed a multi-objective programming model to determine the optimal order quantity. Three objective functions were incorporated into the model. The optimal solution was then used as an input in a DEA model, which was to measure the efficiency effect of the constraints in the multi-objective programming model on the alternative suppliers.

Talluri et al. (2008) utilized a combination of input oriented DEA and multi-objective programming models to determine the negotiation strategies with efficient suppliers. The approach enables effective tailoring of supplier specific negotiations by benchmarking the performance of each potential supplier against the performance of existing suppliers.

\subsubsection{Integrated DEA and SMART}

Seydel (2005) applied SMART approach to evaluate the performance of 10 suppliers. Instead of choosing among suppliers, DEA was applied to evaluate the results of decision making, and to identify a set Pareto efficient outcomes from among a set of candidates.

\subsubsection{Integrated GA and multi-objective programming}

Liao and Rittscher (2007) formulated a multi-objective programming model for supplier selection under stochastic demand conditions. Four objective functions were incorporated into the model. Instead of solving the model to optimality, GA was deployed to select the optimal supplier in an efficient manner. 


\section{Observations and recommendations}

In this paper, 78 journal articles, which appeared in the period from 2000 to 2008, solving the supplier evaluation and selection problem using the multi-criteria decision making approaches were collected. The approaches, including individual and integrated, their applications and evaluating criteria have been summarized in Appendices 1 to 11. Some observations based on these journal articles are made in the following sub-sections.

\subsection{The most popular approach}

The first objective of this paper is to find out the most popular approach adopted in supplier evaluation and selection literature. As found in the previous sections, the individual approaches (46 papers or 58.97\%) were slightly more popular than the integrated approaches (32 papers or $41.03 \%$ ).

According to Appendix 12, the most popular individual approach is DEA, followed by mathematical programming, AHP, CBR, ANP, fuzzy set theory, SMART, and GA. DEA has attracted more attention mainly because of its robustness. In the past, it was used to measure the relative efficiencies of homogeneous DMUs based on numerical data only. As the supplier selection problem involves both qualitative and quantitative criteria, DEA has been modified to handle qualitative data, such as amount of know-how transfer (Saen, 2006), service (Seydel, 2006), supplier reputation (Saen, 2007a), and so on. In addition, it can now be used to consider stochastic performance measures (Talluri et al., 2006), and handle imprecise data (Saen, 2007a; Wu et al., 2007).

As shown in Appendix 13, there are various integrated approaches for supplier selection. It was noticed that the integrated AHP approaches are more prevalent. The wide applicability is due to its simplicity, ease of use, and great flexibility (Ho, 2008). AHP has been integrated with other techniques, including ANN, bi-negotiation, DEA, fuzzy set theory, GP, grey relational analysis, and multi-objective programming. Comparatively, the integrated AHP-GP approach is the most popular. The major reason is that the individual techniques possess unique advantages. The consistency verification operation of AHP contributes greatly to prevent inconsistency because it acts as a feedback mechanism for the decision makers to review and revise their judgments. Consequently, the judgments made are guaranteed to be consistent, which is the basic ingredient for making good decisions. Nevertheless, the output of AHP is the relative importance weightings of criteria and sub-factors merely. In supplier selection problem, besides the weightings of alternative suppliers, the decision makers also need to consider the resource limitations (e.g., budget of buyer and capacities of suppliers). 
For this reason, the GP can compensate for AHP. It can definitely provide more and useful information for the decision makers. Based on the above analysis, it is believed that it must be beneficial to the decision making process if both AHP and GP are integrated together.

\subsection{The most popular evaluating criterion}

The second objective of this paper is to discover the most popular criterion considered by the decision makers for evaluating and selecting the most appropriate supplier. Hundreds of criteria were proposed, and they were summarized in Appendix 14. The most popular criterion is quality, followed by delivery, price/cost, manufacturing capability, service, management, technology, research and development, finance, flexibility, reputation, relationship, risk, and safety and environment.

There are 68 papers (87.18\%) considering quality in the supplier selection process. Various quality related attributes have been found in the papers, such as "acceptable parts per million”, “compliance with quality”, “continuous improvement program, six sigma program or total quality management program”, “corrective and preventive action system”, “documentation and self-audit”, "inspection and control”, "ISO quality system installed”, "low defect rate”, “net rejections”, "non-conforming material control system”, "number of bills received from the supplier without errors", "number of quality staff”, "percentage of products or items not rejected upon inspection”, “perfect rate”, "process control capability”, “quality assurance production”, “quality award”, “quality certification”, “quality data and reporting”, “quality manual”, “quality planning”, “quality management practices and systems”, "reliability of quality”, "rejection in incoming quality”, "rejection in production line”, "rejection from customers”, "service quality credence”, "service quality experience”, "shipment quality", and "training”.

The second most popular criterion is delivery (64 papers or 82.05\%). Its related attributes include "appropriateness of the delivery date”, “compliance with due date”, "degree of closeness”, “delivery and location”, “delivery compliance”, “delivery conditions”, “delivery delays”, “delivery efficiency”, “delivery lead time”, “delivery mistakes”, “delivery performance”, “delivery reliability”, “distance”, “geographical condition”, “geographical location”, "net late deliveries”, “number of shipments to arrive on time”, “order-to-delivery lead time”, “on-time delivery”, "percentage of orders shipped to buyer on or before original promised ship date”, "percentage of orders shipped on or before final ship date”, “percentage of orders delivered by the due date”, “sample delivery time”, “supplier proximity”, and "waiting time". 
The third most popular criterion price/cost (63 papers or $80.77 \%$ ). Its related attributes include "appropriateness of the materials price to the market price”, "competitiveness of cost”, “cost reduction capability”, “cost reduction effort”, “cost reduction performance”, "direct cost”, “fluctuation on costs", “indirect-coordination cost”, "logistics cost”, "manufacturing cost”, “unit cost”, “ordering cost”, “parts price”, “product price”, and "total cost of shipments”.

Based on the above findings, it was revealed that price/cost is not the most widely adopted criterion. The traditional single criterion approach based on lowest cost bidding is no longer supportive and robust enough in contemporary supply management.

\subsection{Limitations of approaches}

The last objective of this paper is to critically analyze the approaches, and try to find out some drawbacks. Instead of analyzing every single approach, the main focus of this section is confined to DEA and AHP-GP, which are the two most popular individual and integrated approaches, respectively. The reasons why these two approaches have attracted more attention can be found in Section 4.1.

There are three limitations or drawbacks of DEA. First, the practitioners may be confused with input and output criteria. For example, some authors considered price/cost as an output criterion (Narasimhan et al., 2001; Talluri and Narasimhan, 2004; Seydel, 2006), whereas the others used it as an input criterion (Liu et al., 2000; Narasimhan et al., 2001; Talluri and Baker, 2002; Talluri and Sarkis, 2002; Talluri and Narasimhan, 2004; Garfamy, 2006; Ross et al., 2006; Saen, 2006; Talluri et al., 2006; Saen, 2007a; Wu et al., 2007). The second problem is due to the subjective assignment of ratings to qualitative criteria. Although Saen (2006) and Seydel (2006) deployed five-point and seven-point scales to rank the priorities of qualitative criteria, respectively, some inconsistencies may be occurred because of the subjective judgments. The third concern is due to the nature of DEA. As discussed earlier, DEA is a linear programming to measure the relative efficiencies of homogenous DMUs. In the other words, those suppliers generating more outputs while requiring less input are regarded as the more efficient suppliers. A question is raised "is an efficient supplier equivalent to an effective supplier?”

In the integrated AHP-GP approach, AHP was used first to determine the relative importance weightings of alternative suppliers with respect to multiple evaluating criteria. The weightings were then incorporated into the GP model to determine the optimal set of suppliers to be selected, and determine the optimal order quantity, while subjecting to some 
resource constraints. There is one potential problem related to AHP. It may be time-consuming in reaching consensus. Decision makers have to compare each cluster in the same level in a pairwise fashion based on their own experience and knowledge. For instance, every two criteria in the second level are compared at each time with respect to the goal, whereas every two sub-factors of the same criteria in the third level are compared at a time with respect to the corresponding criterion. If it is found that the consistency ratio exceeds the limit, the decision makers have to review and revise the pairwise comparisons again.

\subsection{Other observation}

The distribution of the 78 journal articles between 2000 and 2008 is shown in Appendix 15. It is observed that there is a growth in the study of the supplier evaluation and selection problem using the multi-criteria decision making approaches from the first five years (2000 2004) to the recent four years (2005 - 2008), 31 vs. 47. It is estimated that the number will keep increasing in the coming years because of the importance of supplier selection to an effective supply chain.

\section{Future work}

Although the above mentioned approaches can deal with multiple and conflicting criteria, they have not taken into consideration the impact of business objectives and requirements of company stakeholders on the evaluating criteria. In reality, the weightings of supplier evaluating criteria depend a lot on business priorities and strategies. In cases where the weightings are assigned arbitrarily and subjectively without considering the "voice" of company stakeholders, the suppliers selected may not provide what the company exactly wants.

To enable the "voice" of company stakeholders is considered, an integrated analytical approach, combining AHP and QFD, should be developed to select suppliers strategically. Specifically, multiple evaluating criteria are derived from the requirements of company stakeholders using a series of house of quality. The importance of evaluating criteria is prioritized with respect to the degree of achieving the stakeholder requirements using AHP. Based on the ranked criteria, alternative suppliers are evaluated and compared with each other using AHP again to make an optimal selection.

The most important information that the QFD provides is the importance weightings of evaluating criterion, which are derived by the importance ratings of stakeholder requirements together with the relationship weightings between stakeholder requirements and evaluating 
criterion. Generally, both importance ratings of stakeholder requirements and relationship weightings are determined by the decision makers arbitrarily. This may result in a certain degree of inconsistency, and therefore degrade the quality of decisions made. To overcome this drawback, AHP is used to evaluate them consistently. Nevertheless, the proposed AHP-QFD approach has not been applied to the supplier selection problem yet.

\section{Conclusions}

This paper is based on a literature review on the multi-criteria decision making approaches for supplier evaluation and selection from 2000 to 2008. First, it was found that numerous individual and integrated approaches were proposed to solve the supplier selection problem. They are all capable of handling multiple quantitative and qualitative factors. The most prevalent individual approach is DEA, whereas the most popular integrated approach is AHP-GP. Second, it was observed that price or cost is not the most widely adopted criterion. Instead, the most popular criterion used for evaluating the performance of suppliers is quality, followed by delivery, price or cost, and so on. This proves that the traditional single criterion approach based on lowest cost is not supportive and robust enough in contemporary supply management. The traditional cost-based approach cannot guarantee that the selected supplier is global optimal because the customer-oriented criteria (quality, delivery, flexibility, and so on) were not considered. Besides, some recommendations were made based on the inadequacies of some approaches. This can definitely aid the researchers and decision makers in solving the supplier selection problem effectively.

\section{References}

Akarte, M.M., Surendra, N.V., Ravi, B., Rangaraj, N., 2001. Web based casting supplier evaluation using analytical hierarchy process. Journal of the Operational Research Society 52 (5), 511-522.

Amid, A., Ghodsypour, S.H., O’Brien, C., 2006. Fuzzy multiobjective linear model for supplier selection in a supply chain. International Journal of Production Economics 104 (2), 394-407.

Amid, A., Ghodsypour, S.H., O’Brien, C., 2008. A weighted additive fuzzy multiobjective model for the supplier selection problem under price breaks in a supply chain. International Journal Production Economics (in press). 
Baker, R.C., Talluri, S., 1997. A closer look at the use of DEA for technology selection. Computers and Industrial Engineering 32 (1), 101-108.

Barla, S.B., 2003. A case study of supplier selection for lean supply by using a mathematical model. Logistics Information Management 16 (6), 451-459.

Bayazit, O., 2006. Use of analytic network process in vendor selection decisions. Benchmarking: An International Journal 13 (5), 566-579.

Bevilacqua, M., Ciarapica, F.E., Giacchetta, G., 2006. A fuzzy-QFD approach to supplier selection. Journal of Purchasing \& Supply Management 12 (1), 14-27.

Bottani, E., Rizzi, A., 2008. An adapted multi-criteria approach to suppliers and products selection - an application oriented to lead-time reduction. International Journal Production Economics 111 (2), 763-781.

Braglia, M., Petroni, A., 2000. A quality assurance-oriented methodology for handling trade-offs in supplier selection. International Journal of Physical Distribution \& Logistics Management 30 (2), 96-111.

Çebi, F., Bayraktar, D., 2003. An integrated approach for supplier selection. Logistics Information Management 16 (6), 395-400.

Chan, F.T.S., 2003. Interactive selection model for supplier selection process: an analytical hierarchy process approach. International Journal Production Research 41 (15), 3549-3579.

Chan, F.T.S., Chan, H.K., 2004. Development of the supplier selection model - a case study in the advanced technology industry. Proceedings of the Institution of Mechanical Engineers Part B - Journal of Engineering Manufacture 218 (12), 1807-1824.

Chan, F.T.S., Kumar, N., 2007. Global supplier development considering risk factors using fuzzy extended AHP-based approach. OMEGA - International Journal of Management Science 35 (4), 417-431.

Chan, F.T.S., Chan, H.K., Ip, R.W.L., Lau H.C.W., 2007. A decision support system for supplier selection in the airline industry. Proceedings of the Institution of Mechanical Engineers Part B - Journal of Engineering Manufacture 221 (4), 741-758.

Chen, C.T., Lin, C.T., Huang S.F., 2006. A fuzzy approach for supplier evaluation and selection in supply chain management. International Journal of Production Economics 102 (2), 289-301.

Chen, Y.M., Huang, P.N., 2007. Bi-negotiation integrated AHP in suppliers selection. Benchmarking: An International Journal 14 (5), 575-593.

Chou, S.Y., Chang, Y.H., 2008. A decision support system for supplier selection based on a 
strategy-aligned fuzzy SMART approach. Expert Systems with Applications 34 (4), 2241-2253.

Choy, K.L., Lee, W.B., 2002. A generic tool for the selection and management of supplier relationships in an outsourced manufacturing environment: the application of case based reasoning. Logistics Information Management 15 (4), 235-253.

Choy, K.L., Lee, W.B., Lo, V., 2002. Development of a case based intelligent customer supplier relationship management system. Expert Systems with Applications 23 (3), 281-297.

Choy, K.L., Lee, W.B., 2003. A generic supplier management tool for outsourcing manufacturing. Supply Chain Management: An International Journal 8 (2), 140-154.

Choy, K.L., Fan, K.K.H., Lo, V., 2003a. Development of an intelligent customer-supplier relationship management system: the application of case-based reasoning. Industrial Management \& Data Systems 103 (4), 263-274.

Choy, K.L., Lee, W.B., Lo, V., 2003b. Design of a case based intelligent supplier relationship management system - the integration of supplier rating system and product coding system. Expert Systems with Applications 25 (1), 87-100.

Choy, K.L., Lee, W.B., Lo, V., 2003c. Design of an intelligent supplier relationship management system: a hybrid case based neural network approach. Expert Systems with Applications 24 (2), 225-237.

Choy, K.L., Lee, W.B., Lo, V., 2004a. An enterprise collaborative management system - a case study of supplier relationship management. The Journal of Enterprise Information Management 17 (3), 191-207.

Choy, K.L., Lee, W.B., Lau, H.C.W., Lu, D., Lo, V., 2004b. Design of an intelligent supplier relationship management system for new product development. International Journal of Computer Integrated Manufacturing 17 (8), 692-715.

Choy, K.L., Lee, W.B., Lo, V., 2005. A knowledge-based supplier intelligence retrieval system for outsource manufacturing. Knowledge-based systems 18 (1), 1-17.

De Boer, L., Labro, E., Morlacchi, P., 2001. A review of methods supporting supplier selection. European Journal of Purchasing and Supply Management 7 (2), 75-89.

Degraeve, Z., Labro, E., Roodhooft, F., 2000. An evaluation of supplier selection methods from a total cost of ownership perspective. European Journal of Operational Research 125 (1), 34-58.

Demirtas, E.A., Üstün, Ö., 2008. An integrated multi-objective decision making process for supplier selection and order allocation. OMEGA - International Journal of Management 
Science 36 (1), 76-90.

Demirtas, E.A., Üstün, Ö., 2009. Analytic network process and multi-period goal programming integration in purchasing decisions. Computer and Industrial Engineering 56 (2), 677-690.

Ding, H., Benyoucef, L., Xie, X., 2005. A simulation optimization methodology for supplier selection problem. International Journal Computer Integrated Manufacturing 18 (2-3), $210-224$.

Florez-Lopez, R., 2007. Strategic supplier selection in the added-value perspective: a CI approach. Information Sciences 177 (5), 1169-1179.

Forker, L.B., Mendez, D., 2001. An analytical method for benchmarking best peer suppliers. International Journal of Operations and Production Management 21 (1-2), 195-209.

Garfamy, R.M., 2006. A data envelopment analysis approach based on total cost of ownership for supplier selection. Journal of Enterprise Information Management 19 (6), 662-678.

Gencer, C., Gürpinar, D., 2007. Analytic network process in supplier selection: a case study in an electronic firm. Applied Mathematical Modeling 31 (11), 2475-2486.

Ghodsypour, S.H., O’Brien, C., 2001. The total cost of logistics in supplier selection, under conditions of multiple sourcing, multiple criteria and capacity constraint. International Journal of Production Economics 73 (1), 15-27.

Ha, S.H., Krishnan, R., 2008. A hybrid approach to supplier selection for the maintenance of a competitive supply chain. Expert Systems with Applications 34 (2), 1303-1311.

Ho, W., 2008. Integrated analytic hierarchy process and its applications - a literature review. European Journal of Operational Research 186 (1), 211-228.

Hong, G.H., Park, S.C., Jang, D.S., Rho H.M., 2005. An effective supplier selection method for constructing a competitive supply-relationship. Expert Systems with Applications 28 (4), 629-639.

Hou, J., Su, D., 2007. EJB-MVC oriented supplier selection system for mass customization. Journal of Manufacturing Technology Management 18 (1), 54-71.

Huang, S.H., Keska, H., 2007. Comprehensive and configurable metrics for supplier selection. International Journal of Production Economics 105 (2), 510-523.

Jain, V., Tiwari, M.K., Chan F.T.S., 2004. Evaluation of the supplier performance using an evolutionary fuzzy-based approach. Journal of Manufacturing Technology Management 15 (8), 735-744.

Kahraman, C., Cebeci, U., Ulukan, Z., 2003. Multi-criteria supplier selection using fuzzy AHP. Logistics Information Management 16 (6), 382-394. 
Karpak, B., Kumcu, E., Kasuganti, R.R., 2001. Purchasing materials in the supply chain: managing a multi-objective task. European Journal of Purchasing \& Supply Management 7 (3), 209-216.

Kull, T.J., Talluri, S., 2008. A supply-risk reduction model using integrated multi-criteria decision making. IEEE Transactions on Engineering Management 55 (3), 409-419.

Kwong, C.K., Ip, W.H., Chan, J.W.K., 2002. Combining scoring method and fuzzy expert systems approach to supplier assessment: a case study. Integrated Manufacturing Systems 13 (7), 512-519.

Lau, H.C.W., Lee, C.K.M., Ho, G.T.S., Pun, K.F., Choy, K.L., 2006. A performance benchmarking system to support supplier selection. International Journal of Business Performance Management 8 (2-3), 132-151.

Liao, Z., Rittscher, J., 2007. A multi-objective supplier selection model under stochastic demand conditions. International Journal of Production Economics 105 (1), 150-159.

Liu, J., Ding, F.Y., Lall, V., 2000. Using data envelopment analysis to compare suppliers for supplier selection and performance improvement. Supply Chain Management: An International Journal 5 (3), 143-150.

Liu, F.H.F., Hai, H.L., 2005. The voting analytic hierarchy process method for selecting supplier. International Journal of Production Economics 97 (3), 308-317.

Mendoza, A., Santiago, E., Ravindran, A.R., 2008. A three-phase multicriteria method to the supplier selection problem. International Journal of Industrial Engineering 15 (2), 195-210.

Mendoza, A., Ventura, J.A., 2008. An effective method to supplier selection and order quantity allocation. International Journal of Business and Systems Research 2 (1), 1-15.

Muralidharan, C., Anantharaman, N., Deshmukh, S.G., 2002. A multi-criteria group decision-making model for supplier rating. Journal of Supply Chain Management 38 (4), 22-33.

Narasimhan, R., Talluri, S., Mendez, D., 2001. Supplier evaluation and rationalization via data envelopment analysis: an empirical examination. Journal of Supply Chain Management 37 (3), 28-37.

Narasimhan, R., Talluri S., Mahapatra S.K., 2006. Multiproduct, multicriteria model for supplier selection with product life-cycle considerations. Decision Sciences 37 (4), 577-603.

Ng, W.L., 2008. An efficient and simple model for multiple criteria supplier selection problem. European Journal of Operational Research 186 (3), 1059-1067. 
Perçin, S., 2006. An application of the integrated AHP-PGP model in supplier selection. Measuring Business Excellence 10 (4), 34-49.

Ramanathan, R., 2007. Supplier selection problem: integrating DEA with the approaches of total cost of ownership and AHP. Supply Chain Management: An International Journal 12 (4), 258-261.

Ross, A., Buffa F.P., Dröge, C., Carrington D., 2006. Supplier evaluation in a dyadic relationship: an action research approach. Journal of Business Logistics 27 (2), 75-102.

Saen, R.F., 2006. A decision model for selecting technology suppliers in the presence of nondiscretionary factors. Applied Mathematics and Computation 181 (2), 1609-1615.

Saen, R.F., 2007a. Suppliers selection in the presence of both cardinal and ordinal data. European Journal of Operational Research 183 (2), 741-747.

Saen, R.F., 2007b. A new mathematical approach for supplier selection: accounting for non-homogeneity is important. Applied Mathematics and Computation 185 (1), 84-95.

Sarkar, A., Mohapatra, P.K.J., 2006. Evaluation of supplier capability and performance: a method for supply base reduction. Journal of Purchasing \& Supply Management 12 (3), $148-163$.

Sarkis, J., Talluri, S., 2002. A model for strategic supplier selection. Journal of Supply Chain Management 38 (1), 18-28.

Sevkli, M., Koh, S.C.L., Zaim, S., Demirbag, M., Tatoglu, E., 2007. An application of data envelopment analytic hierarchy process for supplier selection: a case study of BEKO in Turkey. International Journal of Production Research 45 (9), 1973-2003.

Seydel, J., 2005. Supporting the paradigm shift in vendor selection: multicriteria methods for sole-sourcing. Managerial Finance 31 (3), 49-66.

Seydel, J., 2006. Data envelopment analysis for decision support. Industrial Management \& Data Systems 106 (1), 81-95.

Talluri, S., 2002. A buyer-seller game model for selection and negotiation of purchasing bids. European Journal of Operational Research 143 (1), 171-180.

Talluri, S., Baker, R.C., 2002. A multi-phase mathematical programming approach for effective supply chain design. European Journal of Operational Research 141 (3), 544-558.

Talluri, S., Narasimhan, R., 2003. Vendor evaluation with performance variability: a max-min approach. European Journal of Operational Research 146 (3), 543-552.

Talluri, S., Narasimhan, R., 2004. A methodology for strategic sourcing. European Journal of Operational Research 154 (1), 236-250. 
Talluri, S., Narasimhan, R., 2005. A note on “a methodology for supply base optimization”. IEEE Transactions on Engineering Management 52 (1), 130-139.

Talluri, S., Sarkis, J., 2002. A model for performance monitoring of suppliers. International Journal of Production Research 40 (16), 4257-4269.

Talluri, S., Vickery, S.K., Narayanan, S., 2008. Optimization models for buyer-supplier negotiations. International Journal of Physical Distribution and Logistics Management 38 (7), 551-561.

Talluri, S., Narasimhan, R., Nair, A., 2006. Vendor performance with supply risk: a chance-constrained DEA approach. International Journal of Production Economics 100 (2), 212-222.

Wadhwa, V., Ravindran, A.R., 2007. Vendor selection in outsourcing. Computers \& Operations Research, 34 (12), 3725-3737.

Wang, G., Huang, S.H., Dismukes, J.P., 2004. Product-driven supply chain selection using integrated multi-criteria decision-making methodology. International Journal of Production Economics 91 (1), 1-15.

Wang, G., Huang, S.H., Dismukes, J.P., 2005. Manufacturing supply chain design and evaluation. International Journal of Advanced Manufacturing Technology 25 (1-2), 93-100.

Weber, C.A., Current, J.R., Benton, W.C., 1991. Vendor selection criteria and methods. European Journal of Operational Research 50 (1), 2-18.

Weber, C.A., Current, J.R., Desai, A., 2000. An optimization approach to determining the number of vendors to employ. Supply Chain Management: An international Journal 5 (2), 90-98.

Wu, T., Shunk, D., Blackhurst, J., Appalla, R., 2007. AIDEA: a methodology for supplier evaluation and selection in a supplier-based manufacturing environment. International Journal of Manufacturing Technology and Management 11 (2), 174-192.

Xia, W., Wu, Z., 2007. Supplier selection with multiple criteria in volume discount environments. OMEGA - International Journal of Management Science 35 (5), 494-504.

Yang, C.C., Chen, B.S., 2006. Supplier selection using combined analytical hierarchy process and grey relational analysis. Journal of Manufacturing Technology Management 17 (7), 926-941. 


\section{Supplementary materials}

\section{Appendix 1}

Data envelopment analysis - applications and evaluating criteria

\begin{tabular}{ll}
\hline Authors & Applications \\
\hline Braglia and Petroni (2000) & Bottling machines and packaging \\
& lines manufacturing
\end{tabular}

\section{Evaluating criteria}

lines manufacturing

Liu et al. (2000)

Agricultural and construction equipment manufacturing

Forker and Mendez (2001)

Electronic components manufacturing

Outputs - Profitability; Quality; Delivery compliance.

Inputs - Management capabilities; Production facilities and capacity; Technological capabilities; Financial position; Experience; Geographical location.

Outputs - Supply variety; Quality. Inputs - Price index; Delivery performance; Distance.

Output - Acceptable parts per million.

Inputs - Role of management leadership and quality policy; Role of the quality department; Training; Product/service design; Supplier quality management; Process management; Quality data and reporting; Employee relations. Inputs - Quality management practices and systems; Documentation and self-audit; Process/manufacturing capability; Management of the firm; Design and development capabilities; Cost reduction capability; Supplier performance assessment.

Outputs - Number of shipments to arrive on time; Number of bills received from the supplier without errors; Service quality experience; Service quality credence.

Inputs - Total cost of shipments; Number of shipments per month.

Outputs - Number of shipments to arrive on time; Number of bills received from the supplier without errors; Service quality experience; Service quality credence.

Inputs - Total cost of shipments; Number of shipments per month. 
Garfamy (2006)

Ross et al. (2006)

Saen (2006)

Seydel (2006)

Talluri et al. (2006)

Saen (2007a)

Wu et al. (2007)
Telecommunications industry

Manufacturing - supplier evaluation and management accounting

Communications industry
Nuclear power industry

Consumer products manufacturing

Pharmaceutical industry

Supply chain management

Aviation electronics manufacturing
Outputs - Quality; Price; Delivery; Cost reduction performance; Other. Inputs - Quality management practices and systems; Documentation and self-audit; Process/manufacturing capability; Management of the firm; Design and development capabilities; Cost reduction capability; Supplier performance assessment.

Output - A unit of product.

Inputs - Manufacturing cost; Quality cost; Input technology; After sales service cost; Price.

Outputs - Percentage of order acknowledgements with a promise ship date within 24 hrs of PO issue; Percentage of suppliers shipping notices received at buyer within 24 hrs of ship date; Percentage of orders shipped to buyer on or before the original promised ship date; Percentage of orders shipped on or before final ship date; Percentage of orders delivered by the due date; Percentage of products/items not rejected upon inspection.

Inputs - Dollar value of contracted; Dollar value of performance incentives associated with contracted items; Purchase order stability; Buyer's forecast accuracy; Buyer's comprehensiveness of forecast.

Outputs - Electricity capacity; Amount of know-how transfer. Input - Cost.

Outputs - Price; Quality; Lead time; Quantity; Delivery; Technology; Service.

Outputs - Quality; Delivery.

Input - Price.

Outputs - Number of bills received from the supplier without errors. Input - Total cost of shipments; Supplier reputation.

Outputs - Revenue; Satisfaction.

Input - Cost; Judgment. 


\section{Appendix 2}

Mathematical programming - applications and evaluating criteria

\begin{tabular}{|c|c|c|c|}
\hline Approach & Authors & Applications & Evaluating criteria \\
\hline Linear programming & $\begin{array}{l}\text { Talluri and Narasimhan } \\
\text { (2003) }\end{array}$ & Pharmaceutical industry & Price; Quality; Delivery. \\
\hline Linear programming & $\begin{array}{l}\text { Talluri and Narasimhan } \\
\text { (2005) }\end{array}$ & $\begin{array}{l}\text { Telecommunications } \\
\text { industry }\end{array}$ & $\begin{array}{l}\text { Quality; Price; Delivery; Cost reduction performance; } \\
\text { Other; Quality management practices and systems; } \\
\text { Documentation and self-audit; Process/manufacturing } \\
\text { capability; Management of the firm; Design and } \\
\text { development capabilities; Cost reduction capability; } \\
\text { Supplier performance assessment. }\end{array}$ \\
\hline Linear programming & $\operatorname{Ng}(2008)$ & $\begin{array}{l}\text { Agricultural and } \\
\text { construction equipment } \\
\text { manufacturing }\end{array}$ & Supply variety; Quality; Distance; Delivery; Price. \\
\hline $\begin{array}{l}\text { Binary integer linear } \\
\text { programming }\end{array}$ & Talluri (2002) & Pharmaceutical industry & Price; Quality; Delivery. \\
\hline $\begin{array}{l}\text { Mixed integer linear } \\
\text { programming }\end{array}$ & Hong et al. (2005) & Agriculture industry & Delivery; Quality; Price; Quantity. \\
\hline $\begin{array}{l}\text { Mixed integer nonlinear } \\
\text { programming }\end{array}$ & $\begin{array}{l}\text { Ghodsypour and O’Brien } \\
\text { (2001) }\end{array}$ & Hypothetical case & $\begin{array}{l}\text { Price; Ordering cost; Perfect rate; On-time delivery; } \\
\text { Capacity. }\end{array}$ \\
\hline Goal programming & Karpak et al. (2001) & $\begin{array}{l}\text { Hydraulic gear pump } \\
\text { manufacturing }\end{array}$ & $\begin{array}{l}\text { Product cost; Quality of castings purchased; Delivery } \\
\text { reliability of castings purchased }\end{array}$ \\
\hline $\begin{array}{l}\text { Multi-objective } \\
\text { programming }\end{array}$ & Narasimhan et al. (2006) & $\begin{array}{l}\text { Personal computer } \\
\text { manufacturing }\end{array}$ & $\begin{array}{l}\text { Direct cost; Indirect-coordination cost; Quality; } \\
\text { Delivery reliability; Complexity of supply arrangement. }\end{array}$ \\
\hline $\begin{array}{l}\text { Multi-objective } \\
\text { programming }\end{array}$ & $\begin{array}{l}\text { Wadhwa and Ravindran } \\
\text { (2007) }\end{array}$ & Hypothetical case & Price; Lead time; Rejects. \\
\hline
\end{tabular}




\section{Appendix 3}

Analytic hierarchy process - applications and evaluating criteria

\begin{tabular}{|c|c|c|}
\hline Authors & Applications & Evaluating criteria \\
\hline Akarte et al. (2001) & Automobile castings & $\begin{array}{l}\text { Maximum casting size; Minimum section thickness; Casting } \\
\text { complexity; Software aid; Pattern making; Sand preparation; Molding; } \\
\text { Core making; Melting and pouring; Heat treatment; Machining; } \\
\text { Dimensional tolerance; Surface roughness; Testing facilities; Quality } \\
\text { certification; Quality awards; Total casting cost; Sample delivery time. }\end{array}$ \\
\hline Muralidharan et al. (2002) & Bicycles manufacturing & $\begin{array}{l}\text { Quality; Delivery; Price; Technical capability; Financial position; Past } \\
\text { performance attitude; Facility; Flexibility; Service. }\end{array}$ \\
\hline Chan (2003) & Manufacturing & $\begin{array}{l}\text { Cost; Quality; Design capability; Manufacturing capability; Technical } \\
\text { capability; Technological capability; Performance history; } \\
\text { Management capability; Degree of cooperation; Financial } \\
\text { performance; Degree of closeness. }\end{array}$ \\
\hline Chan and Chan (2004) & $\begin{array}{l}\text { Semiconductor assembly } \\
\text { equipment manufacturing industry }\end{array}$ & Cost; Delivery; Flexibility; Innovation; Quality; Service. \\
\hline Liu and Hai (2005) & Furniture industry & $\begin{array}{l}\text { Quality; Responsiveness; Discipline; Delivery; Financial; } \\
\text { Management; Technical capability; Facility. }\end{array}$ \\
\hline Chan et al. (2007) & Airline industry & $\begin{array}{l}\text { Cost; Satisfaction of supplier; Quality; Assurance of supplier; } \\
\text { Proactive in measuring supply chain / own suppliers; E-business } \\
\text { initiatives; CI program / six sigma program / TQM program, etc.; } \\
\text { Research and development; Organizational culture and strategic issue; } \\
\text { Compatibility; Perceived risk; Financial issues; Technological issues; } \\
\text { Safety, environmental, and education issues. }\end{array}$ \\
\hline Hou and Su (2007) & Printer manufacturing & $\begin{array}{l}\text { Quality; Cost; Technology; Production capability; R\&D; Delivery \& } \\
\text { Location; Performance \& Service. }\end{array}$ \\
\hline
\end{tabular}




\section{Appendix 4}

Case-based reasoning - applications and evaluating criteria

\begin{tabular}{|c|c|c|}
\hline Authors & Applications & Evaluating criteria \\
\hline Choy and Lee (2002) & $\begin{array}{l}\text { Consumer products } \\
\text { manufacturing }\end{array}$ & $\begin{array}{l}\text { Delivery; Shipment quality; Product price; Manufacturing capability; } \\
\text { Customer service; Management commitment, Product development; } \\
\text { Process improvement; Quality planning; Quality assurance supply; } \\
\text { Quality assurance production; Inspection and experimentation; Quality } \\
\text { staff; Organizational culture; Achievement of sales and marketing } \\
\text { objectives. }\end{array}$ \\
\hline Choy et al. (2002) & $\begin{array}{l}\text { Consumer products } \\
\text { manufacturing }\end{array}$ & $\begin{array}{l}\text { Compliance with due date; Compliance with quality; Rejection in } \\
\text { incoming quality; Rejection in production line; Rejection from } \\
\text { customers; Price; Inquiry response time; Quality staff; Product } \\
\text { development time; Product variety; Product line. }\end{array}$ \\
\hline Choy and Lee (2003) & $\begin{array}{l}\text { Consumer products } \\
\text { manufacturing }\end{array}$ & $\begin{array}{l}\text { Delivery; Shipment quality; Product price; Manufacturing capability; } \\
\text { Customer service; Product innovation; Product development time; } \\
\text { Number of quality staff; Culture innovation; Financial status. }\end{array}$ \\
\hline Choy et al. (2003a) & $\begin{array}{l}\text { Consumer products } \\
\text { manufacturing }\end{array}$ & $\begin{array}{l}\text { Delivery; Shipment quality; Product price; Customer service; Quality; } \\
\text { Development; Organizational culture. }\end{array}$ \\
\hline Choy et al. (2003b) & $\begin{array}{l}\text { Consumer products } \\
\text { manufacturing }\end{array}$ & Same as Choy et al. (2002) \\
\hline Choy et al. (2004a) & $\begin{array}{l}\text { Consumer products } \\
\text { manufacturing }\end{array}$ & Same as Choy et al. (2002) \\
\hline Choy et al. (2005) & $\begin{array}{l}\text { Consumer products } \\
\text { manufacturing }\end{array}$ & $\begin{array}{l}\text { Price; Delivery; Quality; Innovation level; Level of technology; } \\
\text { Culture; Commercial awareness; Production flexibility; Ease of } \\
\text { communication; Current reputation. }\end{array}$ \\
\hline
\end{tabular}




\section{Appendix 5}

Analytic network process - applications and evaluating criteria

\begin{tabular}{|c|c|c|}
\hline Authors & Applications & Evaluating criteria \\
\hline Sarkis and Talluri (2002) & $\begin{array}{l}\text { High technology metal-based } \\
\text { manufacturing }\end{array}$ & Culture; Technology; Relationship; Cost; Quality; Time; Flexibility. \\
\hline Bayazit (2006) & Hypothetical case & $\begin{array}{l}\text { Flexibility; On-time delivery; Price; Delivery lead-time; Quality; } \\
\text { Market share; Personnel capability; Process capability; Top } \\
\text { management capability; Financial capability. }\end{array}$ \\
\hline Gencer and Gürpinar (2007) & Electronic industry & $\begin{array}{l}\text { Facility location; Number of working years; References; Service } \\
\text { capability; Communication capability; Organization structure; Number } \\
\text { of personnel; Education status of the personnel; The last term profit; } \\
\text { Exporting status; Appropriateness of the materials price to the market } \\
\text { price; Machine capacity and capability; Manufacturing technology; } \\
\text { Facilities manufacturing capacity; Technical capability; Manufacturing } \\
\text { planning capability; Handling and packaging capability; } \\
\text { Appropriateness of the quantity; Appropriateness of the delivery date; } \\
\text { Appropriateness of the packaging standards; The period of procuring } \\
\text { materials; Quality system certificate of the supplier; Quality manual; } \\
\text { Documentation control; Archive of quality records; Usage of worth } \\
\text { instructions; Process control capability; Product identification; } \\
\text { Receiving inspection; Calibration control; Non-conforming material } \\
\text { control system; Corrective and preventive action system; Audit } \\
\text { mechanism; Training }\end{array}$ \\
\hline
\end{tabular}




\section{Appendix 6}

Fuzzy set theory - applications and evaluating criteria

\section{Authors}

Chen et al. (2006)

Sarkar and Mohapatra (2006)

Florez-Lopez (2007)

\section{Applications}

High-technology manufacturing

Hypothetical case

Hypothetical case

\section{Evaluating criteria}

Profitability of supplier; Relationship closeness; Technological capacity; Conformance quality; Conflict resolution.

Price; Quality; Delivery lead time; Attitude; Quality systems in operation at the supplier's place; Financial capability of the supplier; Production facilities and capacity; Management and organization; Technological capability; Breadth of product line; Supplier's proximity; Existence of IT standards; Labor problems at the supplier's place; Reputation.

Cost reduction effort; Delivery delays; Price; Reliability; Commit to quality; Responsiveness; Commit to improvement; Delivery mistakes; Fluctuation on costs; Order mistakes; Outgoing quality; Timely communication; Customer service; Technical assistance. 


\section{Appendix 7}

Simple multi-attribute rating technique - applications and evaluating criteria

\begin{tabular}{lll}
\hline Authors & Applications & Evaluating criteria \\
\hline Barla (2003) & Glass manufacturing industry & $\begin{array}{l}\text { Reliability of subcontractor; Capability of subcontractor; Quality } \\
\text { organization; Geographical condition; Financial condition; Service; } \\
\text { Price. }\end{array}$ \\
Huang and Keskar (2007) & PC manufacturing industry & $\begin{array}{l}\text { Reliability; Responsiveness; Flexibility; Cost and financial; Assets and } \\
\text { infrastructure; Safety; Environment. }\end{array}$ \\
\hline
\end{tabular}

\section{Appendix 8}

Genetic algorithm - application and evaluating criteria

\begin{tabular}{lll}
\hline Authors & Application & Evaluating criteria \\
\hline Ding et al. (2005) & Textile industry & $\begin{array}{l}\text { Order-to-delivery lead-time; Ratio of on-time delivery; Inventory } \\
\text { position; Resource utilization; Cost. }\end{array}$ \\
\hline
\end{tabular}




\section{Appendix 9}

Integrated AHP approaches - applications and evaluating criteria

\begin{tabular}{lll}
\hline Approaches & Authors & Applications \\
\hline AHP-Bi-negotiation & Chen and Huang (2007) & $\begin{array}{l}\text { High-end computer } \\
\text { manufacturing }\end{array}$
\end{tabular}

manufacturing

AHP-DEA

AHP-DEA

AHP-DEA

AHP-DEA-ANN

Ha and Krishnan (2008)

Auto parts manufacturing

Saen (2007b)

Sevkli et al. (2007)

Hypothetical case

TV set manufacturing

Hypothetical case

Ramanathan (2007)

AHP-GP

Çebi and Bayraktar (2003) Food manufacturing

\section{Evaluating criteria}

Cash-to-cash cycle time; Inventory days of supply; Order quantity; Visitation to supplier facilities; Performance history; Production flexibility; Quality performance; Position in the industry and reputation; EDI capability; Organization structure; Price; Logistics cost; Value-added productivity; Supply chain response time; Delivery lead time; Fill rate.

Manufacturing costs; Quality; Technology; After-sales service.

Two unknown inputs and two unknown outputs.

Shipment quality; Delivery; Cost; Number of employees; Organizational structure; Training; Number of technical staff; Management commitment; Inspection and control; Quality planning; Quality assurance; Production capacity; Maintenance; Lead-time; Up to date; Storage; Development; Reputation; Location; Price; Patent; Technical capability; RFID; EDI; Internet.

Production facilities; Quality management intention; Quality system outcome; Claims; Quality improvement; Response to claims; On-time delivery; Organizational control; Business plans; Customer communication; Internal audit; Data administration.

Lead time; Supply lots; Flexibility; Delivery conditions; Capacity; Involvement; Improvement effort; Problem solving; Reputation; Financial strength; Management; Communication; Past experience; Sales representative. 


\section{AHP-GP}

AHP-GP

Wang et al. (2005)

Perçin (2006)

\section{AHP-GP}

Kull and Talluri (2008)

\section{AHP-GP}

AHP-grey relational analysis

AHP-mixed integer nonlinear programming

AHP-multi-objective programming

Automobile manufacturing

Automobile manufacturing

Automobile manufacturing

\section{quality; Flexibility; Delivery reliability; Technical capability; Continuous improvement programs;} Technical information sharing; Technological compatibility; Product innovation capabilities; Suppliers' organizational structure; Reputation and position in industry; Financial strength; Management skills; Performance history; Geographical location; Long-term relationship; Response to complaints; Communication systems; Warranty support; Repair and maintenance service.

Delivery risk; cost risk; quality risk; flexibility risk; confidence risk.

products manufacturin

Hypothetical case

Mendoza et al. (2008)

Yang and Chen (2006)

Mendoza and Ventura (2008)

Xia and Wu (2007)
Laptop computer manufacturing

Hypothetical case

Hypothetical case
Flexibility; Quality; Price; Service; Delivery.

Quality; Finance; Customer service; Production capacity; Design \& technical capability; IT system; Turnover; Cost; Delivery; Distance.

Flexibility; Quality; Price; Service; Delivery.

Price; Technical level; Defects; Reliability; On-time delivery; Supply capacity; Repair turnaround time; Warranty period. 
Appendix 10 Integrated fuzzy approaches - applications and evaluating criteria

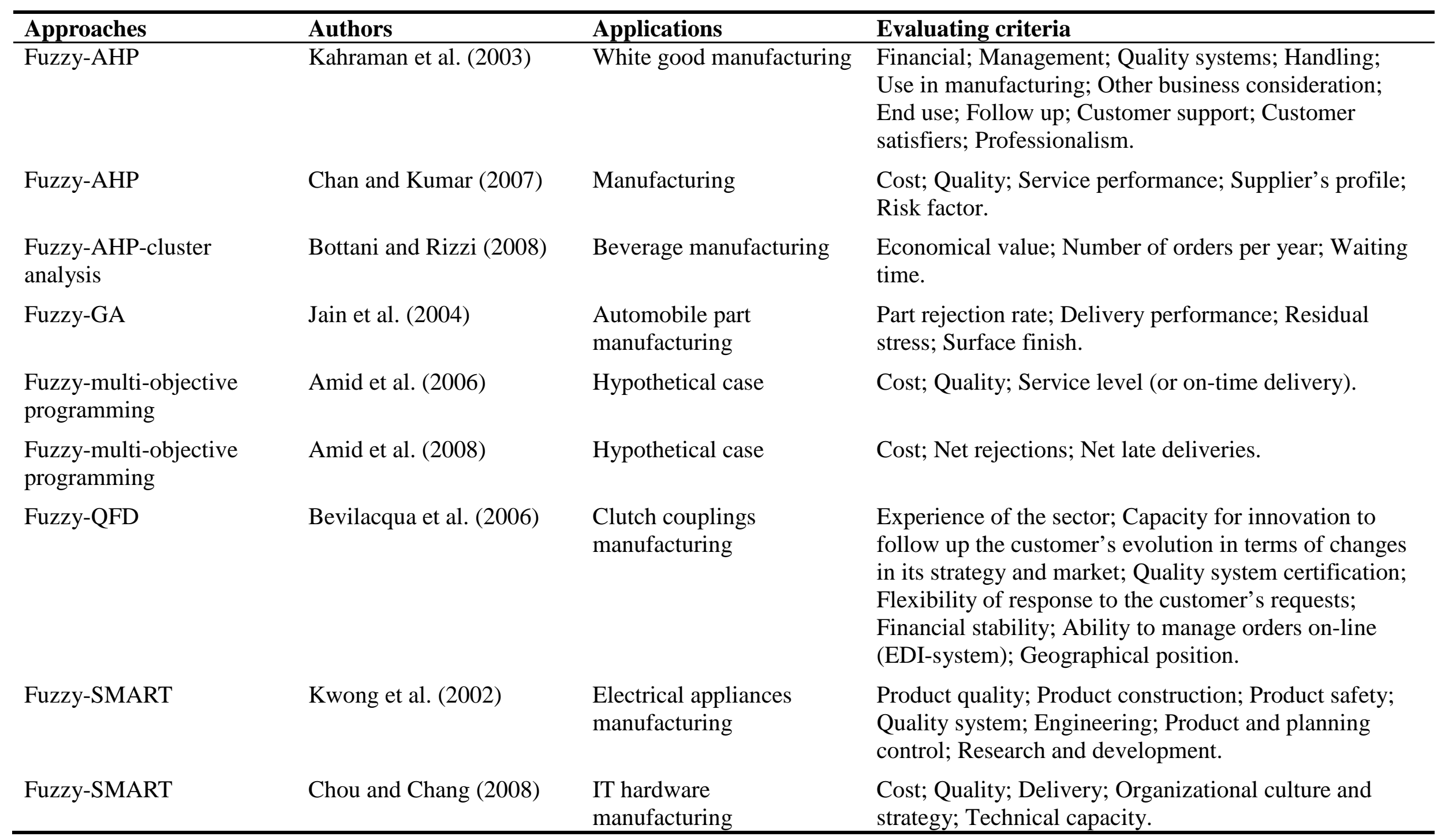




\section{Appendix 11}

Other approaches - applications and evaluating criteria

\begin{tabular}{lll}
\hline Approaches & Authors & Applications \\
\hline ANN-CBR & Choy et al. (2003c) & $\begin{array}{l}\text { Consumer products } \\
\text { manufacturing }\end{array}$
\end{tabular}

Consumer products

\section{Evaluating criteria}

Compliance with due date; Compliance with quality; Rejection in incoming quality; Rejection in production line; Quality system and implementation; Price; Response time; Technical competence; Product development time; Product innovation; Cultural innovation.

ANN-CBR Choy et al. (2004b) $\quad \begin{aligned} & \text { Consumer products } \\ & \text { manufacturing }\end{aligned}$

ANN-GA

Lau et al. (2006)

ANP-multi-objective programming

Demirtas and Üstün (2008)

Demirtas and Üstün (2009)

DEA-multi-objective programming

DEA-multi-objective
Weber et al. (2000)

Talluri et al. (2008)
Hypothetical case

Refrigerator manufacturing

Refrigerator manufacturing

Manufacturing

Pharmaceutical industry
Compliance with due date; Compliance with quality; Rejection in incoming quality; Rejection in production line; Rejection from customers; Parts price; Response time; ISO quality system installed; Product development time; Use of the Internet and database; VMI readiness.

Delivery efficiency; Reliability of quality; Responsiveness to the market trend; Competitiveness of cost.

Low defect rate; Process capability; On-time delivery; Process flexibility; Response to changes; Support to design process; Consistency; Mutual trust and ease of communication; Unit cost; Break in line; Measurement and assessment; Order delays; Customer complaints; Inability to meet further requirements.

Same as Demirtas and Üstün (2008)

Price; Delivery; Quality.

Price; Quality; Delivery. 
programming

DEA-SMART

GA-multi-objective programming
Consumer products manufacturing

Hypothetical case
Quality; Price; Lead time; Quantity; Service; Delivery; Technology.

Cost; Quality; Delivery; Flexibility. 


\section{Appendix 12}

Summary of individual approaches

\begin{tabular}{|c|c|c|}
\hline Approaches & No. of articles & Authors \\
\hline DEA & 14 & $\begin{array}{l}\text { Braglia and Petroni (2000); Liu et al. (2000); } \\
\text { Forker and Mendez (2001); Narasimhan et al. } \\
\text { (2001); Talluri and Baker (2002); Talluri and } \\
\text { Sarkis (2002); Talluri and Narasimhan } \\
\text { (2004); Garfamy (2006); Ross et al. (2006); } \\
\text { Saen (2006); Seydel (2006); Talluri et al. } \\
\text { (2006); Saen (2007a); Wu et al. (2007) }\end{array}$ \\
\hline $\begin{array}{l}\text { Mathematical } \\
\text { programming }\end{array}$ & 9 & $\begin{array}{l}\text { Ghodsypour and O’Brien (2001); Karpak et } \\
\text { al. (2001); Talluri (2002); Talluri and } \\
\text { Narasimhan (2003); Hong et al. (2005); } \\
\text { Talluri and Narasimhan (2005); Narasimhan } \\
\text { et al. (2006); Wadhwa and Ravindran (2007); } \\
\text { Ng (2008). }\end{array}$ \\
\hline AHP & 7 & $\begin{array}{l}\text { Akarte et al. (2001); Muralidharan et al. } \\
\text { (2002); Chan (2003); Chan and Chan (2004); } \\
\text { Liu and Hai (2005); Chan et al. (2007); Hou } \\
\text { and Su (2007) }\end{array}$ \\
\hline CBR & 7 & $\begin{array}{l}\text { Choy and Lee (2002); Choy et al. (2002); } \\
\text { Choy and Lee (2003); Choy et al. (2003a); } \\
\text { Choy et al. (2003b); Choy et al. (2004a); } \\
\text { Choy et al. (2005) }\end{array}$ \\
\hline ANP & 3 & $\begin{array}{l}\text { Sarkis and Talluri (2002); Bayazit (2006); } \\
\text { Gencer and Gürpinar (2007) }\end{array}$ \\
\hline Fuzzy set theory & 3 & $\begin{array}{l}\text { Chen et al. (2006); Sarkar and Mohapatra } \\
\text { (2006); Florez-Lopez (2007) }\end{array}$ \\
\hline SMART & 2 & Barla (2003); Huang and Keskar (2007) \\
\hline GA & 1 & Ding et al. (2005) \\
\hline Total & 46 & \\
\hline
\end{tabular}




\section{Appendix 13}

Summary of integrated approaches

\begin{tabular}{|c|c|c|}
\hline Approaches & No. of articles & Authors \\
\hline AHP-GP & 6 & $\begin{array}{l}\text { Çebi and Bayraktar (2003); Wang et al. } \\
\text { (2004); Wang et al. (2005); Perçin (2006); } \\
\text { Kull and Talluri (2008); Mendoza et al. } \\
\text { (2008) }\end{array}$ \\
\hline AHP-DEA & 3 & $\begin{array}{l}\text { Ramanathan (2007); Saen (2007b); Sevkli et } \\
\text { al. (2007) }\end{array}$ \\
\hline ANN-CBR & 2 & Choy et al. (2003c); Choy et al. (2004b) \\
\hline $\begin{array}{l}\text { DEA-multi-objective } \\
\text { programming }\end{array}$ & 2 & Weber et al. (2000); Talluri et al. (2008) \\
\hline Fuzzy-AHP & 2 & $\begin{array}{l}\text { Kahraman et al. (2003); Chan and Kumar } \\
\text { (2007) }\end{array}$ \\
\hline $\begin{array}{l}\text { Fuzzy-multi-objective } \\
\text { programming }\end{array}$ & 2 & Amid et al. (2006); Amid et al. (2008) \\
\hline Fuzzy-SMART & 2 & Kwong et al. (2002); Chou and Chang (2008) \\
\hline AHP-Bi-negotiation & 1 & Chen and Huang (2007) \\
\hline AHP-DEA-ANN & 1 & Ha and Krishnan (2008) \\
\hline $\begin{array}{l}\text { AHP-grey relational } \\
\text { analysis }\end{array}$ & 1 & Yang and Chen (2006) \\
\hline $\begin{array}{l}\text { AHP-mixed integer } \\
\text { nonlinear } \\
\text { programming }\end{array}$ & 1 & Mendoza and Ventura (2008) \\
\hline $\begin{array}{l}\text { AHP-multi-objective } \\
\text { programming }\end{array}$ & 1 & Xia and Wu (2007) \\
\hline $\begin{array}{l}\text { Fuzzy-AHP-cluster } \\
\text { analysis }\end{array}$ & 1 & Bottani and Rizzi (2008) \\
\hline Fuzzy-GA & 1 & Jain et al. (2004) \\
\hline Fuzzy-QFD & 1 & Bevilacqua et al. (2006) \\
\hline ANN-GA & 1 & Lau et al. (2006) \\
\hline $\begin{array}{l}\text { ANP-multi-objective } \\
\text { programming }\end{array}$ & 1 & Demirtas and Üstün (2008) \\
\hline ANP-GP & 1 & Demirtas and Üstün (2009) \\
\hline DEA-SMART & 1 & Seydel (2005) \\
\hline $\begin{array}{l}\text { GA-multi-objective } \\
\text { programming }\end{array}$ & 1 & Liao and Rittscher (2007) \\
\hline Total & 32 & \\
\hline
\end{tabular}




\section{Appendix 14}

Summary of evaluating criteria

\section{Criteria}

Quality

Delivery

\section{Authors}

Braglia and Petroni (2000); Liu et al. (2000); Weber et al. (2000); Akarte et al. (2001); Forker and Mendez (2001); Ghodsypour and O’Brien (2001); Karpak et al. (2001); Narasimhan et al. (2001); Choy and Lee (2002); Choy et al. (2002a); Kwong et al. (2002); Muralidharan et al. (2002); Sarkis and Talluri (2002); Talluri (2002); Talluri and Baker (2002); Talluri and Sarkis (2002); Barla (2003); Chan (2003); Choy and Lee (2003); Choy et al. (2003a); Choy et al. (2003b); Choy et al. (2003c); Kahraman et al. (2003); Talluri and Narasimhan (2003); Chan and Chan (2004); Choy et al. (2004a); Choy et al. (2004b); Jain et al. (2004); Talluri and Narasimhan (2004); Choy et al. (2005); Hong et al. (2005); Liu and Hai (2005); Seydel (2005); Talluri and Narasimhan (2005); Amid et al. (2006); Bayazit (2006); Bevilacqua et al. (2006); Chen et al. (2006); Garfamy (2006); Lau et al. (2006); Narasimhan et al. (2006); Perçin (2006); Ross et al. (2006); Sarkar and Mohapatra (2006); Seydel (2006); Talluri et al. (2006); Yang and Chen (2006); Chan and Kumar (2007); Chan et al. (2007); Chen and Huang (2007); Chou and Chang (2007); Florez-Lopez (2007); Gencer and Gürpinar (2007); Hou and Su (2007); Liao and Rittscher (2007); Ramanathan (2007); Saen (2007a); Sevkli et al. (2007); Wadhwa and Ravindran (2007); Xia and Wu (2007); Amid et al. (2008); Demirtas and Üstün (2008); Ha and Krishnan (2008); Mendoza and Ventura (2008); Mendoza et al. (2008); Ng (2008); Talluri et al. (2008); Demirtas and Üstün (2009)

Braglia and Petroni (2000); Liu et al. (2000); Weber et al. (2000); Akarte et al. (2001); Ghodsypour and O’Brien (2001); Karpak et al. (2001); Narasimhan et al. (2001); Choy and Lee (2002); Choy et al. (2002); Muralidharan et al. (2002); Sarkis and Talluri (2002); Talluri (2002); Talluri and Baker (2002); Talluri and Sarkis (2002); Barla (2003); Çebi and Bayraktar (2003); Chan (2003); Choy and Lee (2003); Choy et al. (2003a); Choy et al. (2003b); Choy et al. (2003c); Talluri and Narasimhan (2003); Chan and Chan (2004); Choy et al. (2004a); Choy et al. (2004b); Jain et al. (2004); Talluri and Narasimhan (2004); Wang et al. (2004); Choy et al. (2005); Ding et al. (2005); Hong et al. (2005); Liu and Hai (2005); Seydel (2005); Talluri and Narasimhan (2005); Wang et al. (2005); Amid et al. (2006); Bayazit (2006); Bevilacqua et al. (2006); Lau et al. (2006); Narasimhan et al. (2006); Perçin (2006); Ross et al. (2006); Sarkar and Mohapatra (2006); Seydel (2006); Talluri et al. (2006); Yang and Chen (2006); Chen and Huang (2007); Florez-Lopez (2007); Gencer and Gürpinar (2007); Hou and Su (2007); Liao and Rittscher (2007); Sevkli et al. (2007); Wadhwa and Ravindran 
Price/Cost

Manufacturing capability

Service
(2007); Xia and Wu (2007); Amid et al. (2008); Bottani and Rizzi (2008); Chou and Chang (2008); Demirtas and Üstün (2008); Ha and Krishnan (2008); Mendoza and Ventura (2008); Mendoza et al. (2008); Ng (2008); Talluri et al. (2008); Demirtas and Üstün (2009)

Liu et al. (2000); Weber et al. (2000); Akarte et al. (2001); Ghodsypour and O’Brien (2001); Karpak et al. (2001); Narasimhan et al. (2001); Choy and Lee (2002); Choy et al. (2002); Muralidharan et al. (2002); Sarkis and Talluri (2002); Talluri (2002); Talluri and Baker (2002); Talluri and Sarkis (2002); Barla (2003); Chan (2003); Choy and Lee (2003); Choy et al. (2003a); Choy et al. (2003b); Choy et al. (2003c); Talluri and Narasimhan (2003); Chan and Chan (2004); Choy et al. (2004a); Choy et al. (2004b); Talluri and Narasimhan (2004); Wang et al. (2004); Choy et al. (2005); Ding et al. (2005); Hong et al. (2005); Seydel (2005); Talluri and Narasimhan (2005); Wang et al. (2005); Amid et al. (2006); Bayazit (2006); Garfamy (2006); Lau et al. (2006); Narasimhan et al. (2006); Ross et al. (2006); Saen (2006); Sarkar and Mohapatra (2006); Seydel (2006); Talluri et al. (2006); Yang and Chen (2006); Chan and Kumar (2007); Chan et al. (2007); Chen and Huang (2007); Florez-Lopez (2007); Gencer and Gürpinar (2007); Hou and Su (2007); Liao and Rittscher (2007); Ramanathan (2007); Saen (2007a); Sevkli et al. (2007); Wadhwa and Ravindran (2007); Wu et al. (2007); Xia and Wu (2007); Amid et al. (2008); Chou and Chang (2008); Demirtas and Üstün (2008); Mendoza and Ventura (2008); Mendoza et al. (2008); Ng (2008); Talluri et al. (2008); Demirtas and Üstün (2009)

Braglia and Petroni (2000); Liu et al. (2000); Akarte et al. (2001); Ghodsypour and O’Brien (2001); Narasimhan et al. (2001); Choy and Lee (2002); Choy et al. (2002); Muralidharan et al. (2002); Talluri and Sarkis (2002); Barla (2003); Çebi and Bayraktar (2003); Chan (2003); Choy and Lee (2003); Choy et al. (2003b); Choy et al. (2004a); Jain et al. (2004); Talluri and Narasimhan (2004); Hong et al. (2005); Liu and Hai (2005); Seydel (2005); Talluri and Narasimhan (2005); Bayazit (2006); Perçin (2006); Ross et al. (2006); Saen (2006); Sarkar and Mohapatra (2006); Seydel (2006); Yang and Chen (2006); Chen and Huang (2007); Gencer and Gürpinar (2007); Hou and Su (2007); Sevkli et al. (2007); Xia and Wu (2007); Bottani and Rizzi (2008); Chou and Chang (2008); Demirtas and Üstün (2008); Ha and Krishnan (2008); Ng (2008); Demirtas and Üstün (2009)

Choy and Lee (2002); Choy et al. (2002); Muralidharan et al. (2002); Barla (2003); Çebi and Bayraktar (2003); Choy and Lee (2003); Choy et al. (2003a); Choy et al. (2003b); Choy et al. (2003c); Kahraman et al. (2003); Chan and Chan (2004); Choy et al. (2004a); Choy et al. (2004b); Wang et al. (2004); Choy et al. (2005); Liu and Hai (2005); Seydel (2005); Wang et al. (2005); 
Management

Research and Development

Finance
Perçin (2006); Seydel (2006); Yang and Chen (2006); Chan and Kumar (2007); Chen and Huang (2007); Florez-Lopez (2007); Gencer and Gürpinar (2007); Hou and Su (2007); Huang and Keskar (2007); Ramanathan (2007); Sevkli et al. (2007); Xia and Wu (2007); Demirtas and Üstün (2008); Ha and Krishnan (2008); Mendoza and Ventura (2008); Mendoza et al. (2008); Demirtas and Üstün (2009)

Braglia and Petroni (2000); Forker and Mendez (2001); Narasimhan et al. (2001); Choy and Lee (2002); Sarkis and Talluri (2002); Çebi and Bayraktar (2003); Chan (2003); Choy and Lee (2003); Choy et al. (2003a); Choy et al. (2003c); Kahraman et al. (2003); Talluri and Narasimhan (2004); Choy et al. (2005); Liu and Hai (2005); Talluri and Narasimhan (2005); Bayazit (2006); Perçin (2006); Sarkar and Mohapatra (2006); Chan et al. (2007); Chen and Huang (2007); Florez-Lopez (2007); Gencer and Gürpinar (2007); Sevkli et al. (2007); Chou and Chang (2008); Ha and Krishnan (2008)

Braglia and Petroni (2000); Akarte et al. (2001); Muralidharan et al. (2002); Sarkis and Talluri (2002); Chan (2003); Choy et al. (2003c); Choy et al. (2004b); Choy et al. (2005); Liu and Hai (2005); Seydel (2005); Bevilacqua et al. (2006); Chen et al. (2006); Garfamy (2006); Perçin (2006); Sarkar and Mohapatra (2006); Seydel (2006); Yang and Chen (2006); Chan et al. (2007); Chen and Huang (2007); Florez-Lopez (2007); Gencer and Gürpinar (2007); Hou and Su (2007); Ramanathan (2007); Sevkli et al. (2007); Xia and Wu (2007)

Forker and Mendez (2001); Narasimhan et al. (2001); Choy and Lee (2002); Choy et al. (2002); Kwong et al. (2002); Chan (2003); Choy and Lee (2003); Choy et al. (2003a); Choy et al. (2003b); Choy et al. (2003c); Chan and Chan (2004); Choy et al. (2004a); Choy et al. (2004b); Talluri and Narasimhan (2004); Choy et al. (2005); Talluri and Narasimhan (2005); Bevilacqua et al. (2006); Perçin (2006); Yang and Chen (2006); Chan et al. (2007); Hou and Su (2007); Sevkli et al. (2007); Demirtas and Üstün (2008); Demirtas and Üstün (2009)

Braglia and Petroni (2000); Muralidharan et al. (2002); Barla (2003); Çebi and Bayraktar (2003); Chan (2003); Choy and Lee (2003); Kahraman et al. (2003); Wang et al. (2004); Choy et al. (2005); Liu and Hai (2005); Wang et al. (2005); Bayazit (2006); Bevilacqua et al. (2006); Chen et al. (2006); Perçin (2006); Sarkar and Mohapatra (2006); Yang and Chen (2006); Chan et al. (2007); Chen and Huang (2007); Gencer and Gürpinar (2007); Huang and Keskar (2007); Wu et al. (2007); Bottani and Rizzi (2008) 
Flexibility

Reputation

Relationship

Risk

Safety and environment
Muralidharan et al. (2002); Sarkis and Talluri (2002); Çebi and Bayraktar (2003); Chan and Chan (2004); Wang et al. (2004); Choy et al. (2005); Wang et al. (2005); Bayazit (2006); Bevilacqua et al. (2006); Narasimhan et al. (2006); Perçin (2006); Chen and Huang (2007); Huang and Keskar (2007); Liao and Rittscher (2007); Demirtas and Üstün (2008); Mendoza and Ventura (2008); Mendoza et al. (2008); Demirtas and Üstün (2009)

Braglia and Petroni (2000); Muralidharan et al. (2002); Çebi and Bayraktar (2003); Chan (2003); Choy et al. (2005); Bevilacqua et al. (2006); Perçin (2006); Sarkar and Mohapatra (2006); Chen and Huang (2007); Chan and Kumar (2007); Chan et al. (2007); Gencer and Gürpinar (2007); Hou and Su (2007); Saen (2007a); Sevkli et al. (2007)

Sarkis and Talluri (2002); Chen et al. (2006); Perçin (2006)

Chan and Kumar (2007); Chan et al. (2007); Kull and Talluri (2008)

Kwong et al. (2002); Chan et al. (2007); Huang and Keskar (2007) 


\section{Appendix 15}

Distribution of number of journal articles since 2000

\begin{tabular}{ll}
\hline Years & No. of articles \\
\hline 2000 & 3 \\
2001 & 5 \\
2002 & 8 \\
2003 & 9 \\
2004 & 6 \\
2005 & 7 \\
2006 & 14 \\
2007 & 15 \\
2008 & 11 \\
Total & 78 \\
\hline
\end{tabular}




\section{University Library}

\section{- M M N E R VA A gateway to Melbourne's research publications}

Minerva Access is the Institutional Repository of The University of Melbourne

Author/s:

Ho, W;Xu, X;Dey, PK

Title:

Multi-criteria decision making approaches for supplier evaluation and selection: A literature review

Date:

2010-04-01

\section{Citation:}

Ho, W., Xu, X. \& Dey, P. K. (2010). Multi-criteria decision making approaches for supplier evaluation and selection: A literature review. EUROPEAN JOURNAL OF OPERATIONAL RESEARCH, 202 (1), pp.16-24. https://doi.org/10.1016/j.ejor.2009.05.009.

Persistent Link:

http://hdl.handle.net/11343/118668 